Derecho \& Realidad

Núm. 24 • Il semestre de 2014

Facultad de Derecho y Ciencias Sociales, UPTC

ISSN: 1692-3936

\title{
El caso DMG: responsabilidad del Estado susceptible de indemnización por acción de grupo
}

\author{
DMG case: State responsibility suitable \\ of compensation for group action
}

Luis Bernardo Díaz G.*

\section{Resumen}

Análisis de la vulneración de la confianza legítima de los tarjetahabientes que invirtieron sus dineros en la Comercializadora DMG y que lo hicieron basados en la confianza legítima que les inspiraba el que el presidente de la República los instara en dos Consejos Comunales y a que uno de sus hijos hiciera parte de una de las firmas del holding empresarial. Al producirse la intervención estatal, por la fuerza del Grupo Aval y su presidente, y negarse el Estado a devolver la totalidad de sus inversiones y réditos, existe una responsabilidad estatal susceptible de indemnización por medio de la acción de grupo.

\section{Palabras clave}

Confianza legítima, DMG, pirámides financieras, acción de grupo, responsabilidad del Estado.

* Director Centro de Investigaciones Facultad de Derecho UPTC. Doctor en Derecho Constitucional Universidad Complutense de Madrid. Apartado Postal 04 Tunja, Boyacá. luisber2004@yahoo.com 


\begin{abstract}
This is an analysis of the breach of legitimate expectation of cardholders who invested their money in DMG Trade Company and they did so based on the legitimate confidence that the President during two communal councils inspired them, since he invited them to invest in that company and also because one of his sons made part of one of the companies of the holding. As a result of State intervention, by the strength of Grupo Aval and its Chairman, and because of the State refusal to return all their investments and revenues, there is a State responsibility suitable of compensation for group action
\end{abstract}

\title{
Keywords
}

Legitimate trust, DMG, financial pyramids, group action, state responsibility. 


\section{Introducción}

Un numeroso grupo de personas invirtió masivamente indistintas sumas de dinero, individual o colectivamente, en la Comercializadora Grupo DMG S.A. identificada con NIT 900031001-5, sociedad anónima constituida mediante escritura pública número 0001033 del 8 de abril del año 2005, otorgada en la Notaría 35 de Bogotá e inscrita en el Registro Mercantil el 7 de junio de 2005 bajo el número 00994666 del Libro IX, que lleva la Cámara de Comercio de esa misma ciudad. El capital de constitución ascendió a \$100 millones.

Según consta en el certificado de existencia y representación legal expedido el 18 de julio de 2007 por dicha Cámara de Comercio, la Sociedad Grupo DMG S.A. tiene como representante legal principal al señor David Eduardo Helmut Murcia Guzmán, identificado con la cédula de ciudadanía número 80.086.615 de Bogotá y como representante legal suplente a la señora Joanne Ivette León Bermúdez, identificada con la cédula de ciudadanía 52.861.823 de Bogotá. También hacía parte la señora Amparo Guzmán, madre de Murcia. Como dirección para notificaciones judiciales se encuentra inscrita la transversal $24 \mathrm{~N}^{\circ} 57-12$ piso $3^{\circ}$ de Bogotá D.C., aunque es hecho notorio la extradición de Murcia Guzmán hacia los Estados Unidos por presunto lavado de activos.

El Grupo DMG S.A., antes de la suspensión de las actividades por parte del Gobierno nacional, manejaba principalmente tarjetas prepago y contratos de publicidad para promocionarlas. La información extraída de la página web www.dmggrupo.com/ nos describe la siguiente operación:

De acuerdo a la información suministrada por los directores y funcionarios de la Sociedad, la principal actividad que desarrolla la sociedad consiste en la comercialización de bienes o servicios por medio de la venta de tarjetas prepago denominadas -DMG GRUPO - PRODIGY CARD-. Tarjetas estas que, de acuerdo con lo ilustrado sobre el tema por los directivos del Grupo DMG S.A., le permiten a sus adquirientes prepagar bienes y/o servicios que el Grupo DMG S.A. les ofrece, comercializa y/o presta en sus diversos establecimientos de comercio, en su comercializadora virtual, y/o en las diferentes entidades o establecimientos afiliados a esta Sociedad a nivel nacional e Internacional, información que está disponible en la página web.

Para comprar a través de DMG, cada cliente debía adquirir dos tarjetas prepago como las que usan Transmilenio y la telefonía móvil. La diferencia está en que al comprar y cargar las tarjetas de DMG, el comprador se volvía contratista por seis meses, es decir, firma un contrato a término definido con Global Marketing Colombia S.A., en el que se compromete a prestar "servicios como activador de marcas y 
Derecho y Realidad

promotor de publicidad personalizada para activación de diferentes marcas que maneje o manejare el contratante". Dichos contratos deben estar en poder de la interventora, pues no entregaban copia a los clientes.

Publicidad:

De acuerdo con la información suministrada por la sociedad "Grupo DMG S.A.", esta no invierte en publicidad masiva tradicional, ya que ha optado por la publicidad personalizada voz a voz, con el objeto de fidelizar a sus clientes. De ahí que la sociedad ofrece a través del contrato de publicidad personalizada, esto es, cuando el cliente da a conocer al público la existencia de la sociedad, de los bienes y productos, con un beneficio económico a través de diferentes modalidades y planes de mercadotecnia y remunerados mediante tarjetas prepago para consumo, cuyos pagos se hacen a través de la empresa CENCO Tecnología DMG que activa estas tarjetas, con base en las autorizaciones de los Directores de cada Punto.

DMG no era una pirámide sino un holding empresarial que utilizaba un esquema multinivel que impulsaba otras marcas a través de ellos; el nuevo socio o cliente lo que hacía era cargar dos tarjetas prepago, una por valor de $\$ 10.000$ que se denominaba "tarjeta de puntos", a la cual se le cargaba hasta un millón de puntos por pago de publicidad voz a voz, que respaldaba un contrato firmado entre las partes, donde el cliente o socio se comprometía a no hablar mal de la empresa y a traer nuevos socios (este millón de puntos se traduce al común como $100 \%$ de intereses), la otra tarjeta se cargaba con el valor que el cliente quisiera depositar, desde $\$ 100.000$ hasta $\$ 50.000 .000$. El cliente podía adquirir todo tipo de bienes y servicios, desde ropa o artículos para el hogar, hasta carros y viajes de turismo a nivel mundial, por medio de un contrato que aplicaba en dos modalidades: a) a seis meses, durante los cuales no se podía retirar el dinero, una vez pasado el lapso podía retirar el capital más los puntos por publicidad generados en este tiempo, que sumaban el doble de lo aportado; claro está que el capital se retiraba completo siempre y cuando no hubiera hecho uso de la tarjeta. Hago una aclaración: se podía retirar el dinero antes de los seis meses pero se perdía el derecho a reclamar cualquier tipo de puntos, sin embargo el capital sería devuelto en su totalidad. b) A cinco meses, mediante el cual, dependiendo del monto, el nuevo socio podía reclamar mensualmente hasta 100.000 puntos por publicidad, es decir el $10 \%$ de lo depositado.

Realmente una impresionante empresa, que además de trabajar en el ámbito económico y de bienestar social, trabajaba en el posicionamiento de marca, y vendía tan bien su imagen que sus socios crearon y amaron la "Familia DMG". "Fidelizar" clientes con las tarjetas puntos o posicionar marcas, es algo que se practica usualmente en Estados Unidos y en Colombia, como lo veremos más adelante con los almacenes de grandes superficies. Para los usuarios depositantes, DMG era un 
negocio sano de compra-venta de tarjetas DMG prepago, cambiables de inmediato por productos comerciales con un sobrecosto a veces del $30 \%$ pero con la zanahoria de recibir seis meses después un doble valor también en dinero. En DMG se podía comprar desde un par de zapatos hasta una casa, pasando por cruceros por el Caribe, vacaciones para toda la familia, automóviles y hasta mercado: "Se pueden tener todas las tarjetas que su bolsillo aguante", explica uno de sus representantes. "Aquí se le paga a la gente por hacer publicidad, usted se vincula y nosotros le damos ganancias, es decir, entra a ser nuestro empleado, ya que firmamos un contrato de prestación de servicios en el que las ganancias las obtiene mensualmente y lo mejor llevando lo que necesita para su hogar".

El sistema era flexible y atractivo, y los rendimientos dependían de qué buscaba o a qué se comprometía el cliente. Cada uno de ellos recibía tarjetas electrónicas que le permitían comprar los productos o servicios ofrecidos por la firma. Si no usaba la tarjeta, le devolvían el dinero con beneficios. Si llevaba nuevos compradores, también lo premiaban. Esa sería la gran diferencia con las pirámides, donde la remuneración es solo en dinero. A diferencia de las pirámides, que quebraron, en DMG no había cesado un solo pago a ningún cliente hasta cuando fue intervenida por el Gobierno. DMG se presentaba como una comercializadora.

La periodista Jineth Bedoya dice:

En medio de la guerra de Murcia por demostrar que su negocio no tenías sombras, lanzó al mercado las ‘tarjetas inteligentes' y les dio mayor seguridad a los 'ahorradores' con un sistema de captación lícito, sin riesgo de pérdida. 'Nuestros hombres analizaron el sistema de las tarjetas, que era como una de crédito normal, con códigos de barras y sistema electrónico para debitar en los almacenes socios o proveedores de DMG... El 8 de febrero (de 2008) apareció con varios comerciales en la transmisión de televisión de los premios de periodismo CPB. (2009, p. 92 y 93). (Subraya nuestra).

Ello señala la legalidad de la operación financiera.

DMG operaba como operan Comcel, Tigo o Movistar, donde el usuario prepaga una tarjeta y esto le da derecho a utilizar minutos para hacer llamadas telefónicas hasta cubrir el valor prepagado. Y así como Comcel no puede ser catalogada como captadora de dinero por vender estas tarjetas prepago, de idéntica forma, DMG nunca podría ser acusada de ser una captadora de dinero por vender tarjetas de mercado, redimibles un cien por ciento en múltiples establecimientos de comercio situados en la propia sede de DMG o en el supermercado El Trigal. Estas compras se podían efectuar en cualquier momento o redimirse por dinero en un plazo acordado en el momento de hacer la operación. 
La segunda tarjeta era para el pago en dinero de beneficios adicionales que solo se podían cobrar en el plazo acordado entre el depositante y DMG. Sin embargo, DMG no considera que esta última tarjeta constituya pago de intereses, sino que manifiesta que se trata de un pago por un contrato de publicidad personalizada dado que el depositante adquiría el compromiso de difundir la marca y la operación DMG a terceros y vincularlos a la empresa. Lo que indica que perfeccionan sus asesores un contrato de publicidad personalizada. En sus balances, el pago de beneficios a terceros por haberle depositado dinero se contabilizaba como dinero pagado, no como intereses, sino pagado a cambio de un contrato de publicidad para posicionar a la firma de David Murcia. Este es el sistema que utiliza Omnilife -famosa compañía de productos farmacéuticos- para vender sus productos.

Para la operación de DMG fueron consultados expertos y reconocidos juristas y economistas como el exdirector de la DIAN Guillermo Fino, el exvicefiscal Armando Otálora y el exprocurador General Jaime Bernal Cuéllar, entre otros, los cuales avalaron con conceptos estrictos la legalidad de la operación.

DMG era una empresa legalmente creada y realizaba actividades de comercialización de bienes y servicios, a través de la venta de tarjetas prepago como lo hacen Comcel, Movistar, Tigo, SodexhoPas, Carrefour, Éxito, Fenalco, Codensa, etc. La venta de tarjetas prepago, para la venta de bienes y servicios, es una actividad lícita en Colombia y muchas empresas la realizan para diferentes operaciones como venta de minutos de celular, o para compra de bienes y servicios, y en varios casos se entregan premios en muchos eventos a través de estas tarjetas prepago, ya que la persona paga por adelantado su consumo. Por otro lado, DMG reconocía a sus clientes unos puntos, por la publicidad que hacían de la entidad y sus servicios, como lo hacen otras empresas o compañías de televisión, radio y otros medios masivos de comunicación, con la única diferencia que los gastos que ocasionan terminan en los usuarios de DMG y no en los medios de comunicación masiva. Además, AV Villas del Grupo Aval tiene un sistema similar de puntos implementado posterior al de DMG al tiempo de ofrecer servicios igualmente, pero esto no ha sido considerado irregular ${ }^{1}$. El 4 de junio de 2008, DMG abrió una sucursal en Tocaima, cuya gerencia fue ejercida por José Luis Ibarra, sobrino del alcalde. La relación allí de DMG con el alcalde ha sido abierta, pues esta empresa financiaba al parecer las fiestas populares de fin de semana en el municipio y era el cliente más importante de doña Nancy Donado, principal distribuidora de cerveza; la

\footnotetext{
La comunicación suscrita por el vicepresidente comercial del Banco AV Villas, Orlando Forero Gómez, fechada el 1 de abril de 2009, dice: "El Banco AV Villas ofrece a sus clientes personas naturales, como incentivo estrictamente comercial y unilateral sujeto al reglamento del programa, la oportunidad de acumular puntos por la adquisición y utilización de productos y/o (sic) servicios que el Banco establece, así como ganar puntos por presentar personas nuevas al Banco que adquieran alguno de los productos que hacen parte del programa...(fidelización!).
} 
fiesta más reciente se organizó en el mes de agosto con motivos de las festividades de San Jacinto, patrono del municipio.

Las relaciones de David Murcia con la prensa quedaron evidenciadas cuando el periodista Jorge Lesmes y el humorista Guillermo Díaz Salamanca de RCN Radio presentaron su renuncia al reconocer haber tenido convenios o acuerdos con DMG. "La órdenes de publicidad que recibimos en RCN, incluidas las emisoras locales de algunas ciudades como Tunja, Sogamoso y Tumaco, ascendieron a la suma exacta de \$35.893.572”, según un aparte del comunicado de Fernando Molina Soto, presidente de la Cadena Radial RCN. Además, el Círculo de Periodistas de Bogotá CPB anunció su voluntad de devolver una suma que oscila alrededor de los \$30 millones recibida de la firma DMG Fashion como pago de la pauta publicitaria en la transmisión de los premios que otorga la asociación de periodistas. Pero, aunque las directivas del CPB reconocieron dicho recibimiento, la presidenta del $\mathrm{CPB}$, Maura Achury, declaró "que la junta del gremio había consultado con la Superintendencia Financiera y la DIAN sobre los posibles procesos que pudieran existir en contra de la filial, cuya respuesta fue que para la fecha no había ninguna investigación abierta, aunque obviamente tenían muchos rumores".

Por si fuera poco, DMG Fashion obtuvo dos premios en Miami en el primer semestre de 2008, por lo cual el propio presidente de Colombia, Álvaro Uribe, extendió a esta firma una carta de felicitación que fue presentada por Noticias Uno en la sección Top Secret.

La siguiente es la lista de personajes que tuvieron relación con DMG:

-Senador Samuel Arrieta, de Convergencia Ciudadana. Se reunió con directivos de DMG, hacía eventos en la sede de DMG.

-Luis Guillermo Giraldo, exembajador y exsecretario del partido de la U. Admite que aceptó los servicios gratuitos de la transportadora de valores Transval, del Grupo DMG, para guardar en una de sus bodegas los folios con las firmas reeleccionistas del presidente Álvaro Uribe, y su posterior traslado en camiones blindados de Transval hasta la Registraduría Nacional del Estado Civil. David Murcia habló de haber contribuido por este medio con la suma de $\$ 5$ mil millones para el referendo reeleccionista de Uribe.

-Ómar Díazgranados, gobernador del Magdalena, con el aval del Partido de la U. Estaba en el mismo apartamento donde se hallaban los socios de Murcia al momento de ser capturados.

-César Mauricio Velásquez, secretario de Prensa de la Presidencia de la República, reconoció que se reunió con Murcia para conocer una propuesta para transmitir programas institucionales en el canal Body Channel, del cual hacía parte el hijo de Uribe. 
-Jorge Armando Otálora, exvicefiscal General de la Nación. Cercanía con Daniel Ángel, socio de Murcia.

-El general retirado Miguel Maza Márquez, exdirector nacional del DAS. Él mismo aceptó que asesoró a Provitec, la empresa de seguridad del Grupo DMG.

-Pedro Alonso Sanabria, magistrado del Consejo Superior de la Judicatura. -Francisco Rojas Birry, personero de Bogotá.

En noviembre de 2007 DMG organizó en Playa Mendoza, un condominio a 40 kilómetros de Barranquilla, una cumbre con numerosos personajes para hablar de temas relacionados con presupuesto, contrataciones, planes de desarrollo y obras sociales. Los gobernadores electos de la Guajira, Jorge Pérez; Putumayo, Felipe Guzmán (amigo de David Murcia), y Magdalena, Omar Díazgranados, eran invitados de honor. Joaco Berrío, gobernador de Bolívar, también fue invitado, pero no asistió por estar fuera del país. Platino Entertainment -filial de DMG- regentó el contrato para la atención de los invitados. DMG contrató una carroza para el Carnaval de Barranquilla en 2007. El magistrado del Consejo Superior de la Judicatura, Pedro Alonso Sanabria, recibió \$400 millones de DMG cuando aspiró a la gobernación de Boyacá, y el personero de Bogotá, Francisco Rojas Birry, recibió \$200 millones. Más de dos mil efectivos de la Fuerza Pública invirtieron recursos en DMG. Igualmente, el Festival de la Leyenda Vallenata, el municipio de Tocaima, RCN-Radio, el Círculo de Periodistas de Bogotá, y otras importantes entidades recibieron apoyos, patrocinios o estímulos económicos de DMG.

El 6 de diciembre de 2008, Jerónimo Uribe, hijo del presidente de la República, tan hábil para los negocios (ver affaire de la Zona Franca de Mosquera con su hermano), admitió a una revista de circulación semanal en Colombia, el haber sostenido una relación comercial con una empresa de la Comercializadora DMG; la empresa de artesanías 'Salvarte' de propiedad de Jerónimo y Tomás Uribe, hijos del mandatario, quien estuvo presente en diciembre de 2006 en el lanzamiento del Canal Body Channel, de propiedad de la polémica DMG. En la investigación realizada, Jerónimo Uribe aceptó haber tenido 'una pequeña relación comercial' pero solo con Daniel Ángel Rueda, primer renglón de la junta directiva de Body Channel S.A. Canal del Cuerpo S.A. Explicó que para el lanzamiento del canal envió cerca de 15 prendas para que lucieran las modelos, asegurando que no se recibió por ello 'pago alguno'.

David Murcia llegó a tener un canal privado de TV pasando por su propia empresa transportadora de valores Transval, la cual era manejada por su cuñado, quien transportó sin costo alguno las firmas a favor del referendo para otra reelección más de Álvaro Uribe Vélez. Murcia calculó en \$5.000 millones la cifra de apoyos financieros y de diversa naturaleza para la recolección de firmas para el referendo del presidente Uribe, como ya lo dije. 
Las empresas del Holding DMG en Colombia eran: DMG Constructores, DMG Comercializadora Virtual, Factory Models, DMG Fashion, Hosset Stylelife Productos naturales, El Gran Trigal, Inmuno Vida, Bussines System, Studio Pilates, Body Channel, Humnor Channel, Pabón Castro Abogados, L\&A, Cenco, Provitec, Searching People, Personal Collection, Funerales DMG, DMG TV, Pollo.com, Droguería DMG, Supermercados DMG, Centros de Estética, Ferretería DMG, DMG Comunicaciones, Abarrotes DMG, Cultivos de Savia, Farmasentry (farmacia), Productos Naturales DMG, DMG Diseño y Arquitectura. En la edición especial de la revista Dinero, "Las 5.000 Empresas", el Grupo DMG S.A. figuró ubicado en el puesto 31 dentro de las empresas más grandes de productos al por mayor con 4 millones de inversionistas.

De acuerdo con el precitado certificado expedido por la Cámara de Comercio de Bogotá D.C., la Sociedad DMG tiene objeto social claramente determinado.

Desde su creación hasta la intervención del Gobierno nacional en noviembre de 2008, la Sociedad DMG estuvo honrando sus compromisos sagradamente y jamás hubo retrasos o incumplimiento de sus obligaciones, por lo cual se veía la puntualidad de la firma.

DMG pagó \$56.000 millones en impuestos a la DIAN mientras estuvo operando (Ortiz 2008, p. 174).

El Gobierno nacional expide el decreto 4333 de 17 de noviembre de 2008, para declarar el estado de emergencia social, sustentado en que "la inclinación de muchos ciudadanos por obtener beneficios desorbitantes, los ha llevado a depositar sus recursos en estas empresas cuyas operaciones se hacen sin autorización, desconociendo las reiteradas advertencias del Gobierno nacional", las cuales no fueron conocidas por los inversionistas, dado que numerosos miembros del poder ejecutivo, legislativo y judicial acudieron a DMG para realizar transacciones, incluso un asesor del propio presidente de la República en la Casa de Nariño para las regiones.

El 17 de noviembre de 2008 el Gobierno nacional expide el decreto 4334, sustentándolo en que

Se han presentado conductas y actividades sobrevinientes por parte de personas naturales y jurídicas que atentan contra el interés público protegido por el artículo 335 de la C.P., en tanto que por la modalidad de captadores o recaudadores en operaciones no autorizadas tales como pirámides, tarjetas prepago, venta de servicios y otras operaciones y negociaciones, generan abuso del derecho y fraude a la ley al ocultar en fachadas jurídicas legales, el ejercicio no autorizado de la actividad financiera, causando graves perjuicios 
al orden social y amenazando el orden público, tal como fue expresado en el decreto de Declaratoria de Emergencia, razón por la cual el Gobierno Nacional debe adoptar urgentes medidas con fuerza de ley que intervengan de manera inmediata las conductas, operaciones y el patrimonio de las personas involucradas y en las de quienes amenazan con desarrollarlas en adelante.

Indubitablemente, como lo dijeron los medios de comunicación, estaba la mano de la gran banca comercial en el origen de estas disposiciones, en especial del Grupo Aval y de su máximo jerarca, Luis Carlos Sarmiento Angulo, que veía afectados sus dividendos con la presencia de DMG, que no era una pirámide como otras. A una persona con tarjeta débito o crédito le descuentan el cuatro por mil, además de la cuota de manejo y los intereses sobre las tarjetas de crédito son de las más altas del mundo. DMG no cobraba eso, sino que entregaba beneficios.

En síntesis, el primer decreto (número 4334) define el proceso administrativo de intervención, los nuevos procedimientos que se adelantarán y la toma de posesión con fines de intervención en los negocios, operaciones y patrimonio de las personas naturales o jurídicas que desarrollen o participen en la actividad financiera sin la debida autorización estatal.

Igualmente, se definen los procesos para efectuar los inventarios de activos y tramitar rápidamente las solicitudes de devolución presentadas por las personas vinculadas al caso.

Determina también los criterios que tendrá en cuenta el agente interventor, para la devolución de los dineros entregados por el público a estas firmas captadoras.

Así mismo, este decreto se aplicará a los procesos de devolución de dineros que estaban en poder de la 'pirámide' Drfe'.

El segundo (número 4335) decreto concede a los alcaldes obligaciones y facultades de policía para tomar las medidas cautelares, tales como sellamiento de establecimientos y custodia, para suspender de manera inmediata la actividad de captación o recaudo masivo de dineros del público o la realización de actividades no autorizadas. El gobernador, cuando tenga conocimiento, tendrá la obligación de avisarle al alcalde, para que tome las medidas correspondientes.

El tercer decreto (número 4336) redefine las conductas sancionables desde el punto de vista penal, retoma el objetivo de endurecimiento y aumento de las penas para quienes realicen o colaboren con la captación masiva no autorizada de recursos del público. Estas penas oscilarán entre 120 y 240 meses y multa de cincuenta mil salarios mínimos legales mensuales. Este delito también se convierte en excarcelable. 
El mismo decreto establece un nuevo tipo de delito, que señala que quien haya captado recursos del público y no lo reintegre, por esa sola conducta, incurrirá en prisión de 96 a 180 meses, y multa de 133.33 a 15 mil salarios mínimos legales vigentes. Este delito tampoco será excarcelable.

En este último delito, por la falta de devolución de dineros antes de la vigencia de esta norma, los fiscales que conozcan de los procesos podrán aplicar de manera preferente el principio de oportunidad en la devolución de los recursos.

El estado de emergencia fue prorrogado mediante decreto legislativo 4704 de 2008 por el término de 30 días contados a partir del 15 de diciembre del mismo año. Para conjurar la situación de anormalidad profirió varias disposiciones entre las cuales se encuentra el decreto 045 de enero de 2009. El Gobierno justificó la medida argumentando que

A pesar de lo anterior han venido proliferando de manera desbordada en todo el país, distintas modalidades de captación o recaudo masivo de dineros del público no autorizados bajo sofisticados sistemas que han dificultado la intervención de las autoridades. Que con base en las falsas expectativas generadas por los inexplicables beneficios ofrecidos, un número importante de ciudadanos ha entregado sumas de dinero a captadores o recaudadores no autorizados, comprometiendo su patrimonio.

Como vemos, son completamente inanes las razones de la intervención para el caso de DMG, pues no era una figura de "captación masiva de dinero" sino una comercializadora; tampoco es cierto que se generaran "falsas expectativas" pues DMG siempre cumplió lo prometido hasta el día de la intervención; "inexplicables beneficios" no es un argumento de peso legal, pues obedece a una fórmula de marketing suficientemente explicada.

El sistema bancario colombiano capta dinero de los ahorradores o inversionistas ofreciendo en retribución $10 \%$ anual como tasa de ahorro, mientras que por conceder un crédito (de consumo, hipotecario, tarjetas de crédito, leasing, etc.) cobra las máximas tasas de interés permitidas por el Gobierno, en múltiples casos cercanos a $30 \%$ con una tasa de intermediación sin precedente en América Latina -el doble que la tasa de intermediación de la banca chilena-, que generan trimestralmente destacadísimas utilidades bancarias. En tarjetas de crédito se llega al exceso de cobrar $32,15 \%$. No existe mayor negocio en el mundo occidental que traer capital golondrino (pasajero) que internacionalmente cuesta $4 \%$ y ponerlo a rentar en Colombia a $30 \%$, en un país en el que el riesgo de devaluación en los últimos 8 años no supera en promedio el $10 \%$ y, al contrario, desde hace años se presenta la revaluación. La diferencia radica en que DMG sí distribuía ganancias entre sus 
inversionistas, mientras que la banca tradicional no lo hace jamás, por lo cual tiene impresionantes ganancias al término de sus ejercicios. En Colombia mandan más los banqueros que el presidente.

Adicionalmente la queja de los usuarios y damnificados de DMG es la bajísima bancarización que existe en Colombia que no alcanza al $20 \%$ de la población, mientras en algunos países europeos la bancarización -es decir, el porcentaje de personas que tienen cuenta de ahorros o corriente en la banca de su país, se acerca al 90 \% de la población adulta-. En Colombia solo tendría acceso al sector bancario un porcentaje mínimo de la sociedad -la que tiene más recursos-, y allí en el sector social de bajos ingresos, marginado por los bancos, DMG encontró un campo de expansión tres veces más amplio que el de los bancos, hablando poblacionalmente. En un país de 44 millones de personas con una bancarización de solo 18 o $20 \%$, DMG tendría un inmenso potencial de expansión, pues en pocos años más de 4 millones de colombianos se habían beneficiado de los elevadísimos réditos de sus dineros entregados a DMG.

Es evidente -mirando un vídeo de David Murcia en Youtube- que hubo una declaración del Holding DMG contra el Grupo Aval (principal grupo financiero de Colombia) y contra su presidente Luis Carlos Sarmiento Angulo, a quienes responsabiliza de "lo que pueda pasarle a él, su familia y sus empresas, según Murcia, por la persecución desatada contra DMG y el cierre de sus cuentas en los bancos del Grupo". El inmenso poder de este banquero se vio cuando llamó al presidente Uribe para que ordenara cesar el paro judicial indefinido en 2008 (porque le afectaba sus negocios), por lo cual dictó medidas de conmoción interior para conjurarlo, las cuales fueron posteriormente declaradas inexequibles por la Corte Constitucional.

La Superintendencia de Sociedades consideró procedente la intervención en los negocios, operaciones y patrimonio de DMG, mediante la medida de toma de posesión para devolver las sumas de dinero supuestamente aprehendidas o recuperadas, designando una agente interventora que actúa al intervenir por orden legal a las empresas DMG, como liquidadora de la sociedad DMG Grupo Holding S.A.

La diferencia entre las pirámides y DMG consiste en que el sistema de pirámides hacía la devolución del dinero y los rendimientos financieros en cierto tiempo, mientras que DMG entregaba de inmediato una tarjeta de puntos a cambio del dinero depositado, con el cupo de la inversión para ser gastado de inmediato adquiriendo productos comerciales y electrodomésticos y a cambio de un contrato de publicidad de cada tarjetahabiente para difundir DMG, el usuario podía en un tiempo determinado recibir elevados rendimientos. 
Mediante decreto se nombró a la señora María Mercedes Perry interventora de DMG, procediendo a señalar que solo devolvería la suma de $\$ 230.000$ a cada "damnificado" de DMG. La irrisoria cifra no era ni una aproximación siquiera lejana de las millonarias sumas invertidas por nuestros poderdantes. Anteriormente se habilitaron las oficinas del Coliseo el Campín en Bogotá para recibir las tarjetas de DMG para cuantificar el "monto invertido".

Ya lo dijo el periodista Mauricio Baena Velásquez:

Lo más extraordinario de todo este asunto es la indiferencia o negligencia de un Estado que ha mostrado firmeza en combatir la delincuencia y el crimen organizado en general, no es fácil entender cómo pudo ser tan vulnerable ante el fenómeno de las captadoras ilegales, con toda la determinación que ha demostrado en tantos otros casos de ilegalidad. Muchos de los afectados aún se preguntan ¿si eran empresas ilegales, por qué el Estado fue tan condescendiente y permitió que engañaran a millones de colombianos al darles los permisos correspondientes en las alcaldías y cámaras de comercio locales? Este elefante blanco funcionó ante los ojos del mundo entero y con la complicidad del Estado, así no lo parezca, pues se acepta que hubo negligencia ante estas empresas ilegales y no se hizo nada oportuno para impedir su funcionamiento sabiendo que, desde hace muchos años, en Colombia existen normas en contra de este flagelo. Es cierto que la gente tiene un alto índice de responsabilidad en el asunto, pero ¿dónde estaban las autoridades que tenían la obligación de decirle al ciudadano del común que este juego iría en detrimento de su economía?, ¿Dónde estaban las campañas del Estado en contra de estas captadoras?, ¿dónde estaban la DIAN, la Policía inteligente del país, la Fiscalía?, ¿dónde los Alcaldes, gobernadores y servidores públicos en general para decirle a la gente que eso era indebido? Tal vez estaban muy ocupados contando sus grandes utilidades, o sobornando a los guardias de estas empresas para que los dejaran ingresar primero y evitarse las filas. Porque soy consciente de que en el Estado hay servidores públicos de muy buena fe y con hojas de vida intachables, no puedo no tengo el derecho a juzgarlos a todos pero sí a los que actuaron de manera negligente, se cubrieron los ojos y no hicieron nada para impedir esta hecatombe en la que se encuentran envueltos millones de colombianos. (2009, p. 28 y 29).

Agrega Baena Velásquez:

La responsabilidad es individual, dice la ley ¿pero qué Ley se aplica cuando un Estado comete una omisión de esta magnitud?, ¿Cuándo recibió miles de millones en impuestos de presuntas empresas ilegales que no se aplican a la reparación de las víctimas? Lo que se observa con claridad es que las medidas 
adoptadas por el Gobierno nacional fueron tomadas con la "cabeza caliente" como se dice popularmente, se presume que el Presidente de la República no manejaba con claridad el tema con el que se estaba metiendo y mucho menos se imaginó la magnitud de la tragedia social que se crearía a raíz de la caída de estas empresas y la posterior intervención a DMG, la empresa que después de 7 años de cumplirle a cabalidad a la gente resultó ilegal e insolvente, sabiendo que en muchas ocasiones figuró en las listas de importantes revistas de economía y de actualidad nacional, como una de las empresas más prósperas y con excelente manejo administrativo, a la par de otras reconocidas empresas colombianas. Sigue la pregunta ¿por qué es ilegal esta empresa después de tantos años en el mercado y con un campo de acción tanto nacional como internacional? (Baena, 2009, p. 102-103).

En derecho se habla del principio de confianza legítima.

La Corte Constitucional en relación con tal principio, ha manifestado:

Así pues, en esencia la confianza legítima consiste en que el ciudadano debe poder evolucionar en un medio jurídico estable y previsible, en el cual pueda confiar. Para Muller, este vocablo significa, en términos muy generales, que ciertas expectativas, que son suscitadas por un sujeto de derecho en razón de un determinado comportamiento en relación con otro, o ante la comunidad jurídica en su conjunto, y que producen determinados efectos jurídicos; y si se trata de autoridades públicas, consiste en la obligación para las mismas de preservar un comportamiento consecuente, no contradictorio frente a los particulares, surgido en un acto o acciones anteriores, incluso ilegales, salvo interés público imperioso contrario.

Se trata, por tanto, que el particular debe ser protegido frente a cambios bruscos e inesperados efectuados por las autoridades públicas. En tal sentido, no se trata de amparar situaciones en las cuales el administrado sea titular de un derecho adquirido, ya que su posición jurídica, es susceptible de ser modificada por la Administración, es decir, se trata de una mera expectativa en que una determinada situación de hecho o regulación jurídica no serán modificadas intempestivamente. De allí que el Estado se encuentre, en estos casos, ante la obligación de proporcionarle al afectado un plazo razonable, así como los medios, para adaptarse a la nueva situación.

De igual manera la doctrina foránea considera que, en virtud del principio de la confianza legítima, la administración pública no le exigirá al ciudadano más de lo estrictamente necesario para la realización de los fines públicos que en cada caso persiga. No obstante, la jurisprudencia extranjera también ha 
considerado que el mencionado principio no es absoluto, que es necesario ponderar su vigencia con otros principios fundamentales del ordenamiento jurídico, en especial con la salvaguarda del interés general en materia económica.

(...).

En suma el principio de confianza legítima es un corolario de aquel de la buena fe y consiste en que el Estado no puede súbitamente alterar unas reglas de juego que regulaban sus relaciones con los particulares, sin que se les otorgue a estos últimos un período de transición para que ajusten su comportamiento a una nueva situación jurídica. No se trata, por tanto, lesionar o vulnerar derechos adquiridos, sino tan sólo de amparar unas expectativas válidas que los particulares se habían hecho con base en acciones u omisiones estatales prolongadas en el tiempo, bien que se trate de comportamientos activos o pasivos de la administración pública, regulaciones legales o interpretaciones de las normas jurídicas. De igual manera, como cualquier otro principio, la confianza legítima debe ser ponderada, en el caso concreto, con los otros, en especial, con la salvaguarda del interés general y del principio democrático" (sentencia C-131 de 2003).

La Procuraduría General de la Nación en concepto de febrero 26 de 2009, dentro del proceso de revisión constitucional del decreto legislativo 045 del 14 de enero de 2009 "Por el cual se dictan medidas para contrarrestar los efectos de la crisis social generada por la actividad de los captadores o recaudadores de dineros del público en operaciones no autorizadas", manifestó que "en el presente caso, se tiene que el Decreto 045 de 2008 no cumple con los parámetros constitucionales que estructuran una relación de conexidad directa con las causas que originaron la declaratoria de la emergencia social y tampoco contiene medidas tendientes a conjurar la crisis o a impedir sus efectos".

El representante a la Cámara, Óscar Gómez Agudelo, dejó constancia en la plenaria de la corporación el 25 de noviembre de 2008 (carta al presidente Álvaro Uribe [Gaceta del Congreso, 2009, p. 17]. Se anexaron 85 folios con 4.000 firmas de afectados):

Como quindianos que somos, afectados con el alto índice de desempleo en esta zona del país, nos vimos en la obligación de aprovechar una oportunidad que ninguna entidad financiera en Colombia en tiempo alguno los hubiera podido ofrecer y por ello confiamos nuestros recursos económicos a DMG, la cual, aparentemente se encontraba en la legalidad, ya que ésta se encontraba registrada en la Cámara de Comercio de Armenia, en la DIAN, en la Secretaría de Gobierno Municipal que controla los establecimientos de comercio y no 
había por qué desconfiar de la misma, al tener más de cuatro mil asociados en la región, los cuales venían obteniendo dividendos por sus recursos entregados.

Para nosotros, quienes votamos por usted, es muy triste saber que a esta hora nuestra plata está embolatada, ya que no ha habido mucha claridad por parte de los funcionarios para la devolución de nuestros dineros... No es justo que se persiga a esta entidad, cuando hay otras como El Éxito, Carrefour, Olímpica y las mismas millas que entrega Avianca en sus vuelos, y que después se pueden convertir en pasajes y otras que operan en el país, sin mayores contratiempos, las cuales pertenecen a empresarios colombianos que apoyaron su campaña.

Nosotros, los afectados que cada que comprábamos un electrodoméstico, un vehículo, ropa u otros accesorios, en cada uno de los recibos nos descontaban lo correspondiente al IVA, o cuando nos hacían devolución de dineros o entregábamos los mismos, también teníamos que pagar una retención la cual pasaba a hacer parte de las finanzas del Estado. Por ello, entregamos fotocopia de los recibos que tenían el visto bueno de la DIAN en todo el país. Esto deja claro Señor Presidente, que no había tanta ilegalidad, ya que veníamos operando sin contratiempos, hace más de 3 años y nada se había hecho-. ,

Los bancos o entidades financieras con sus altos intereses en los préstamos o hipotecas o créditos a través de tarjetas, nos obligó (sic) a encontrar alternativas como las que ofrecía DMG en todo el país y adicionalmente cuando depositábamos nuestros ahorros que eran obtenidos con el fruto de nuestro trabajo, las ganancias eran mínimas y el descuento del cuatro por mil y del manejo de las tarjetas era insostenible, al punto que el dinero estaba más seguro debajo de un colchón.

Es increíble, como lo vimos en los medios de comunicación, señor Presidente, que el Secretario Privado, doctor Bernardo Moreno Villegas, haya manifestado que conocía la situación de DMG mucho tiempo atrás y que su primo hermano era uno de los directivos en Bogotá, y sólo hasta hoy día, usted salga a poner orden a esta difícil situación que se viene presentando en casi todos los municipios colombianos.

¿Qué va a pasar con el Ministro de Hacienda, el Director de la DIAN, con los asesores económicos de su Gobierno, con los representantes de la Superbancaria, con los Directores de la Cámara de Comercio, Secretarios de Gobierno y su mismo Secretario General de la Presidencia? que omitieron acción alguna a tiempo para evitar este caos económico del país, afectando con su posición a miles de colombianos. 
Por último señor presidente, es de suma importancia que en cada región se nombre un interventor para que agilice el proceso de devolución de nuestro dinero, ya que todas las situaciones no son las mismas para cada persona y adicionalmente los recursos decomisados en el eje cafetero que sobrepasan los cuarenta mil millones de pesos, deberían ser devueltos a las personas que habitan en esta zona del país y que pertenecen a DMG, con sus documentos y las respectivas tarjetas que certifican su legalidad. (Anexaron en siete folios el pago del IVA y la DIAN).

Por su parte, la señora Martha Erazo, representante de los damnificados de DMG en Putumayo, ese mismo día dijo lo siguiente en la plenaria:

En nombre del pueblo del Putumayo, sólo hemos venido a denunciar y dejar clara la desaforada y repentina intervención estatal en el caso de DMG, no solo por lo exagerada, desmedida y abrupta, sino porque en ella el Señor Presidente de la República olvida que toda esa crisis sólo es producto de su omisión en el cumplimiento de los deberes que la Constitución Nacional le impone.

Venimos a recordarle al señor Álvaro Uribe, que el artículo 189 numeral 24 de la Carta, establece que corresponde al Presidente de la República como Jefe de Estado, Jefe de Gobierno y Suprema Autoridad Administrativa, ejercer de acuerdo con la ley, la inspección, vigilancia y control sobre las personas que realicen actividades financieras, bursátil, aseguradora y cualquier otra relacionada con el manejo, aprovechamiento o inversión de recursos captados del público, así mismo sobre las entidades cooperativas y las sociedades mercantiles.

...Hasta que el Gobierno del señor Álvaro Uribe hizo lo contrario, DMG ha hecho perder la fe en los bancos a la gente, ya que entiende que eso es crecer millonariamente sin que sus intereses sean siquiera mínimos para con sus ahorradores, y en cambio sí son exagerados con las cuotas cuando se le debe algún crédito y peor situación se vivencia, si un colombiano está atrasado con una o dos cuotas, se remata y embarga lo poco que han conseguido en años y esto no le duele a nuestro presidente. Ha hecho que las personas le pierdan el respeto a un Gobierno, que cuando está de su conveniencia, elude las responsabilidades y aprueba la ilegalidad.

Como vernos, la acción de grupo está llamada a prosperar porque durante varios años de existencia de DMG y solo hasta noviembre de 2008, el Gobierno nacional captó impuestos, validó la inscripción en cámaras de comercio y aceptó como legales todas sus operaciones, hasta el día en que Luis Carlos Sarmiento se molestó, 
Derecho y Realidad

llamó al presidente y entonces -como ocurrió en el paro judicial- este último declaró el estado de conmoción interior y dictó los decretos de intervención en la sociedad. Se dice que en los consejos comunales de Garagoa e Ipiales Uribe llamó incluso a invertir en DMG.

Y prosigue la víctima:

La Ley 734 de 2002 en su artículo 27 trata de la acción y omisión, y el art. 34 de la misma ley, deberes de todo servidor público. Analizo señor Presidente y demás miembros presentes, si esa ley también fue vulnerada y sobrepasada con estas actuaciones que permitió este Gobierno.

Señor Presidente y miembros Representantes, no permitan que el Estado sea el protagonista de la violación de Derechos Fundamentales consagrados en nuestra Carta Constitucional. Derechos que van conectados al Derecho a la Vida y al Trabajo, entre los más importantes.

El Putumayo fue saqueado por distintas pirámides en más de $\$ 300.000$ millones, lo que significaría para recuperarse en su territorio tan pobre, habría que esperarnos 30 años; mientras tanto, qué va a hacer el Gobierno para afrontar la más dura crisis que cruza el departamento por la lentitud y negligencia en la toma de decisiones y por el incumplimiento a la normatividad existente; acciones que se debieron tomar en su momento y por negligencia DIRECTA del Estado es éste quien debe indemnizar al pueblo colombiano y no arbitrariamente tildar o hacer juegos matemáticos que lo único que conllevan es aumentar la injusticia social".

Existieron numerosas denuncias por presunto "lavado de dinero" contra DMG, "por captar dinero del público con tarjetas prepago", por "lavado de activos", por el funcionamiento de "otras pirámides", contra los impulsores del referéndum reeleccionista de Uribe por utilizar la firma Transval del entorno DMG, "por utilizar firmas de DMG lavadoras de dinero", "contra el magistrado Pedro Alonso Sanabria” por recibir $\$ 400$ millones de DMG, contra el Personero de Bogotá Francisco Rojas por recibir \$200 millones, todas firmadas por el abogado Germán Guevara Ochoa, y ninguna de las quejas o denuncias falló en contra de DMG o terminó responsabilizando a algunos de los beneficiarios de DMG, lo cual demuestra la legalidad de la firma y la forma en que el Estado validó permanentemente por medio de los organismos de control las actividades lícitas de la comercializadora. Está pendiente el proceso por presunto lavado en USA.

En conclusión, la nación colombiana (Superintendencia de Sociedades), de conformidad con lo ordenado en el artículo 90 de la Constitución Política, es 
administrativamente responsable de los perjuicios materiales y morales causados a los tarjetahabientes de DMG, por falla o falta del servicio de la Administración que condujo a la pérdida de sus dineros, pues incurrió en omisión al no determinar a tiempo la supuesta ilicitud en que incurrió DMG durante los años de funcionamiento de la comercializadora, bajo los argumentos expuestos en los decretos de intervención y toma de posesión de DMG dictados a la luz de los decretos de conmoción interior, pero además porque la actividad de DMG es la misma que realizan en la actualidad firmas como Movistar, Tigo, Comcel, Olímpica, Carrefour, Éxito, Codensa, AV Villas, Fenalco y Avianca, entre otras, amparadas por la legalidad.

Se debe, en consecuencia, condenar a la nación colombiana -Superintendencia de Sociedades- como reparación del daño ocasionado, a pagar a los actores y demás integrantes del grupo, indemnizaciones individuales a todos y cada uno de ellos, o a quien represente legalmente sus derechos, por los perjuicios de orden material y moral, subjetivados y objetivados, actuales y futuros, estimándose los primeros como mínimo en la suma de OCHOCIENTOS MIL MILLONES DE PESOS M. Cte. (\$800.000.000.000), o conforme a lo que resulte probado dentro del proceso, consistentes en el lucro cesante y daño emergente.

Como ha dicho la Corte Constitucional en sentencia SU 360 de 1999 refiriéndose al principio de confianza legítima:

Es éste un principio que debe permear el derecho administrativo, el cual, si bien se deriva directamente de los principios de seguridad jurídica, de respeto al acto propio y buena fe, adquiere una identidad propia en virtud de las especiales reglas que se imponen en la relación entre administración y administrado. Es por ello que la confianza en la administración no sólo es éticamente deseable sino jurídicamente exigible. Este principio se aplica como mecanismo para conciliar el conflicto entre los intereses público y privado, cuando la administración ha creado expectativas favorables para el administrado y lo sorprende al eliminar súbitamente esas condiciones. Por lo tanto, la confianza que el administrado deposita en la estabilidad de la actuación de la administración, es digna de protección y debe respetarse. Lo anterior no significa que las autoridades están impedidas para adoptar modificaciones normativas o cambios políticos para desarrollar planes y programas que consideran convenientes para la sociedad. Lo prudente es que antes del desalojo se trate de concertar y concretar, con quienes estén amparados por la confianza legítima, un plan de reubicación u otras opciones que los afectados escojan, la administración convenga y sean factibles de realizar o de principiar a ser realizadas.

El principio de la buena fe se presenta en el campo de las relaciones administrado y administración, “en donde juega un papel no sólo señalado en el ámbito del 
ejercicio de los derechos y potestades, sino en el de la constitución de las relaciones y en el cumplimiento de los deberes, comporta la necesidad de una conducta leal, honesta, aquella conducta que, según la estimación de la gente, puede esperarse de una persona” (González, 2014, p. 43).

La buena fe incorpora el valor ético de la confianza. En razón a esto tanto la administración como los administrados deben actuar conforme a las exigencias de la buena fe, sin olvidar "Que el derecho nunca debe ser manejado de espaldas a su fundamento ético que debe ser el factor informante $y$ espiritualizador" (González, 2014, p. 59). Lo anterior implica que, así como la administración pública no puede ejercer sus potestades defraudando la confianza debida a quienes con ella se relacionan, tampoco el administrado puede actuar en contra de aquellas exigencias éticas.

La aplicación del principio de la buena fe permitirá al administrado recobrar la confianza en que la administración no va a exigirle más de lo que estrictamente sea necesario para la realización de los fines públicos que en cada caso concreto persiga. Y en que no le va a ser exigido en su lugar, en el momento ni en la forma más inadecuados, en atención a sus circunstancias personales y sociales, y a las propias necesidades públicas. Confianza legítima de que no se le va a imponer una prestación cuando sólo, superando dificultades extraordinarias podrá ser cumplida. (González, 2014, p. 59)

La organización administrativa del Estado reposa sobre el principio del interés general. Es claro que la contraposición entre los intereses puramente particulares de los individuos aisladamente considerados, y los intereses generales, ha de resolverse necesariamente a favor de los intereses generales, pues lo colectivo debe primar sobre lo individual, y lo público sobre lo privado. Así lo consagran de manera expresa los artículos $1^{\circ}$ y 63 de la Constitución Política de Colombia. El Principio del interés general a su vez determina el contenido y campo de aplicación del principio de la confianza legítima. Pues en él, la confianza legítima encuentra su más claro límite. En tal sentido lo señaló El Tribunal Europeo de Justicia en Sentencia de 16 de mayo de 1979: "al estudiar el conflicto que surgió entre el principio de la confianza legítima y el interés público, a lo cual determinó que” en caso de enfrentamiento el interés público tendrá primacía sobre la confianza legítima: Teniendo en cuenta que el marco de una reglamentación económica como la de las organizaciones comunes de los mercados agrícolas, el principio del respeto de la confianza legítima prohíbe a las instituciones comunitarias modificar esta reglamentación sin combinarla con medidas transitorias, salvo que un interés público se oponga a la adopción de tal medida. (García, 1989, p. 461) 
Retomando el tema de la confianza legítima en la teoría administrativa: la relación entre administración y administrado plantea el gran problema de establecer las delimitaciones legales de los derechos de éstos últimos frente a la administración. Que en virtud de su potestad y ejercicio de las finalidades del Estado pueden ser limitados. Potestad que determina la imprescriptibilidad de los bienes de uso público por la ocupación temporal de los particulares, (art. 63 C.P.) Pero al mismo tiempo, la confianza legítima como medida de protección a los administrados se origina cuando de un acto de aplicación de una norma, aun procedente del poder legislativo, supone para sus destinatarios un sacrificio patrimonial que merece un calificativo especial, en comparación del que pueda derivarse para el resto de la colectividad.

El problema de tal trato, fue resuelto por el principio de protección de la Confianza legítima, que formulado por la jurisprudencia alemana, hizo suyo el Tribunal Europeo de Justicia en Sentencia del 13 de julio de 1965. Sobre este principio los tratadistas García de Enterría y Fernández señalan (2013, p. 375):

Dicho principio, no impide, al legislador modificar las regulaciones generales con el fin de adaptarlas a las exigencias del interés público, pero sí, le obliga a dispensar su protección, en caso de alteración sensible de situaciones en cuya durabilidad podían legítimamente confiar los afectados. Esa modificación legal, obliga a la administración a proporcionarles en todo caso tiempo y medios, para reequilibrar su posición o adaptarse a la nueva situación, lo que dicho de otro modo implica una condena de los cambios bruscos adoptados por sorpresa y sin las cautelas aludidas. (Sent. T-398/97 Corte Constitucional)

\section{Procedencia de la acción de grupo}

La concepción en derecho público sobre responsabilidad fundada en el régimen de falta o falla del servicio afirma que dicha falla no es general, ni absoluta, sino condicionada a la existencia de determinadas circunstancias, tales como queja expresa de control, inspección y vigilancia dirigida a la autoridad con capacidad funcional, de conformidad con las exigencias y formalidades establecidas en las leyes. Por tanto, se puede imputar responsabilidad a la administración por omisión en el ejercicio de sus funciones cuando la competencia es reglada y corresponde a la autoridad pública dar entrada al ejercicio de estas, a través de las quejas o acciones correspondientes, como se acusa en la causa petendi, fue el accionar de un número plural de personas, pertenecientes a este grupo que instaura la acción.

Existen condiciones uniformes respecto de una misma causa que originó para el grupo perjuicios individuales, tales condiciones uniformes existen igualmente, respecto a los elementos que configuran la responsabilidad, existe una situación 
común en la que se colocó este grupo de personas con antelación a la ocurrencia del daño.

En razón de lo anterior están legitimados para ejercer esta acción, porque no es el daño el que origina este grupo, ya que éste es preexistente a la ocurrencia del mismo, puesto que se formó alrededor de una situación común en que se colocaron sus miembros, y, con ocasión de la cual, posteriormente, todos sufrieron el daño.

En conclusión, mediante la acción de grupo puede entablarse la responsabilidad por omisión del Estado para conseguir la indemnización de los afectados que realizaron inversiones en la Comercializadora DMG, independiente de la suerte que corran sus máximos gestores, hoy extraditados a Estados Unidos.

\section{Referencias}

Baena, M. (2009). Captadores de ilusiones. Damnificados de las pirámides. Bogotá: Mondadori.

Bedoya, J. (2009). La pirámide de David Murcia. Bogotá: Planeta.

Carta al presidente Álvaro Uribe (2009, 30 de enero). Gaceta del Congreso (15), 17.

García, R. (1989). Contenido y límites del principio de la confianza legítima. En Homenaje al profesor José Luis Villar Palasí. Madrid: Civitas.

García de Enterría, E. \& Fernández, T. R. (2013). Curso de derecho administrativo. Madrid: Civitas.

González, J. (2014). El principio general de la buena fe en el derecho administrativo, Madrid: Civitas.

Ortiz, J.G. (2008). DMG David Murcia Guzmán. ¿Héroe o villano? Bogotá: Oveja Negra. 